\title{
Sementes de pulses: situação atual e perspectivas
}

\author{
Pulse seeds: current situation and perspectives \\ Semillas de pulso: situación actual y perspectivas
}

Recebido: 03/09/2021 | Revisado: 10/09/2021 | Aceito: 13/09/2021 | Publicado: 14/09/2021

Francine Bonemann Madruga

ORCID: https://orcid.org/0000-0001-7202-7462

Universidade Federal de Pelotas, Brasil

E-mail: francinebonemann@hotmail.com

Carem Rosane Coutinho Saraiva

ORCID: https://orcid.org/0000-0002-0810-2402

Universidade Federal de Pelotas, Brasil

E-mail: caremsaraiva@ hotmail.com

Henrique Berle

ORCID: https://orcid.org/0000-0002-4094-4642

Universidade Federal de Pelotas, Brasil

E-mail: Henriqueberle@ hotmail.com

Mateus da Silveira Pasa

ORCID: https://orcid.org/0000-0003-0481-0206

Universidade Federal de Pelotas, Brasil

E-mail: mateus.pasa@gmail.com

Lilian Vanussa Madruga de Tunes

ORCID: https://orcid.org/0000-0001-7562-1926

Universidade Federal de Pelotas, Brasil

E-mail: lilianmtunes@yahoo.com.br

Andréia da Silva Almeida

ORCID: https://orcid.org/0000-0003-3169-6787

Universidade Federal de Pelotas, Brasil

E-mail: andreiasalmeida@yahoo.com.br

\begin{abstract}
Resumo
As sementes de pulses são sementes secas proveniente de leguminosas, que possuem uma importância mundial devido os benefícios que trazem a saúde, essas sementes movimentam o mercando econômico tanto o mercado interno como o externo devido à crescente demanda tanto da índia como de outros países. Por essa razão está revisão bibliográfica tem como objetivo descrever o cenário e produção e comercialização de sementes de pulses de lentilha, Feijão, Grãode-bico e Ervilha. No que tange a situação atual dessas sementes de pulses citadas acima é que há pouca demanda por sementes de pulses e as pessoas tem uma certa preferência dietética por tipos específicos de pulses, preço e disponibilidade no mercado como mostra os resultados apresentados neste trabalho, em relação a perspectiva é que a sementes de pulses dobre a sua produção com o passar dos anos devido à grande procura, demanda e por preços mais acessíveis.
\end{abstract}

Palavras-chave: Sementes; Pulses; Produção; Consumo.

\begin{abstract}
Pulse seeds are dry seeds from pulses, which are of global importance due to the benefits they bring to health, these seeds move the economic market both domestically and abroad due to the growing demand from both India and other countries. For this reason, this literature review aims to describe the scenario and production and marketing of pulses seeds of lentil, beans, chickpeas and peas. Regarding the current situation of these pulses seeds mentioned above, there is little demand for pulses seeds and people have a certain dietary preference for specific types of pulses, price and availability in the market, as shown by the results presented in this paper, in relation the perspective is that pulses seeds will double its production over the years due to high demand, demand and more affordable prices.
\end{abstract}

Keywords: Seeds; Pulses; Production; Consumption.

\section{Resumen}

Las semillas de legumbres son semillas secas de legumbres, las cuales son de importancia mundial por los beneficios que aportan a la salud, estas semillas mueven el mercado económico tanto a nivel nacional como en el exterior debido a la creciente demanda tanto de India como de otros países. Por ello, esta revisión de la literatura tiene como objetivo describir el escenario y la producción y comercialización de semillas de legumbres de lentejas, frijoles, garbanzos y guisantes. Con respecto a la situación actual de estas semillas de legumbres mencionadas anteriormente, existe poca 
demanda de semillas de legumbres y las personas tienen cierta preferencia dietética por tipos específicos de legumbres, precio y disponibilidad en el mercado, como lo demuestran los resultados presentados en este trabajo, en relación la perspectiva es que las semillas de legumbres duplicarán su producción a lo largo de los años debido a la alta demanda, la demanda y los precios más asequibles.

Palabras clave: Semillas; Pulsos; Producción; Consumo.

\section{Introdução}

Derivado do latin Puls, as sementes de pulses são sementes secas provenientes de leguminosas secas quando cozidos, esses grãos produzem um caldo grosso, ou até mesmo uma sopa grossa, o que justifica o termo Pulses. Segundo a (FAO, 2016), são classificadas mais de onze espécies de sementes de pulses, sendo quatro são mais conhecidas e consumidos no como: ervilhas secas, feijão, lentilhas e grão de bico são as espécies mais comuns. Os pulses vem se destacando cada dia mais em questão de segurança alimentar e nutricional pois essas sementes são ricas em proteínas, fibras, várias vitaminas e aminoácidos. Devido a essas qualidades os pulses geram saúde e até mesmo salvam vidas da desnutrição, diabetes, obesidade e da fome (FAO, 2016).

Em diferentes partes do País o consumo de sementes de pulses vem aumentando, logo não está sendo suficiente para atender a grande demanda de consumidores pois os mesmos tem preferência dietética por tipos específicos de pulses, preço e disponibilidade no mercado. Embora as previsões mostram um pequeno aumento nas áreas cultivadas com pulses ainda não é muito significativo, pois projeções indicam que é necessário um crescimento de 19 milhões de toneladas para 39 milhões de toneladas, até 2050, mais do que o dobro da produção atual, baseadas no incremento de área a ser adicionada ao cultivo de pulses no País e no aumento da produtividade (EMBRAPA ,2018).

Com a crescente demanda do mercado interno por sementes de pulses, o Brasil e a Índia poderiam fazer acordos para fortalecer o fornecimento de pulses, pois a demanda na Índia gera desafios ao setor agrícola, como esgotamento das águas subterrâneas, perda de terras agrícolas para uso industrial, residencial e comercial e incertezas devido aos caprichos das chuvas sazonais (EMBRAPA, 2016).

No Brasil, a produtividade de leguminosas secas vem aumentando devido as inovações tecnológicas e práticas utilizadas na pesquisa e desenvolvimento proveniente de estudos realizados pela Empresa Brasileira de Pesquisa Agropecuária (EMBRAPA), na qual optem por experiência e êxodo nesse tipo de pesquisa. Porém segundo (EMBRAPA, 2016), as práticas agrícolas recomendadas é o de cultivo em plantio direto, em mais de $75 \%$ da terra sob culturas na qual ajuda a melhorar a conservação da umidade e matéria orgânica, prevenindo assim a degradação e erosão do solo, aumento da produtividade e diminuição de despesas, tornando sua agricultura sustentável.

Objetivo desse trabalho de revisão bibliográfica é mostrar a situação atual e perspectivas das principais sementes de pulses no Brasil e no mundo como o Feijão, Ervilha, Lentilha e Grão-de-Bico.

\section{Metodologia}

\subsection{Legislação}

A legislação da produção de sementes em geral está organizada de acordo com os padrões e as normas específicas estabelecidos pelo Ministério da Agricultura, Pecuária e Abastecimento (MAPA), que tem como o objetivo disponibilizar material de multiplicação vegetal com garantia de identidade e qualidade das sementes.

De acordo com o (MAPA), surge as instituições normativas, como por exemplo a INSTRUÇÃO NORMATIVA N ${ }^{\circ}$ 45, DE 17 DE SETEMBRO DE 2013, para sementes de feijão e ervilha, na qual estabelece os padrões de identidade e qualidade para a produção e a comercialização de sementes, além das exigências estabelecidas nesta Instrução Normativa a 
produção e a comercialização de sementes das espécies referidas no art. $1^{\circ}$ deverão atender aos requisitos fitossanitários estabelecidos pela legislação específica, garantia da ausência ou da presença de semente adventícia de Organismo Geneticamente Modificado (OGM) em lote de semente de cultivar convencional é de exclusiva responsabilidade do produtor.

No que tange a INSTRUÇÃO NORMATIVA No 42, DE 17 DE SETEMBRO DE 2019, para semente de lentilha, estabelece assim como para sementes de feijão e ervilhas normas para a Produção e a Comercialização de Sementes e Mudas de Espécies Olerícolas, Condimentares, Medicinais e Aromáticas e os seus padrões de sementes, com validade em todo o território nacional, visando à garantia de sua qualidade e identidade, na forma desta Instrução Normativa e de seus anexos que fala que seus padrões de identidade e de qualidade para a produção e a comercialização de sementes de espécies olerícolas, condimentares, medicinais e aromáticas, além dos termos para a produção desse tipo de sementes, oriundo do produtor, os tipos de embalagem na qual pode ser armazenada esse tipo de semente. Já para Grão-de-Bico não se têm uma instrução normativa ou legislação especifica para sementes.

Importante ressaltar que essas Instruções Normativas estabelecido pelo (MAPA), sobre sementes, fala em produção e sementes no geral, pois não existe nada especifico sobre produção de sementes de pulses não existe nada conivente para esse tipo de grupo, apenas fala na produção como um todo.

As sementes de pulse são considerados por alguns experts mundiais como o alimento mais nutritivo e que traz inúmeros benefícios para a saúde humana, pensando nisso e da sua importância surge o Guia Alimentar para a População Brasileira que fala da importância da alternância entre diferentes tipos de leguminosas, na qual surge a necessidade de diversificação dos Feijões no consumo do brasileiro, bem como o dos demais Pulses (ervilhas, lentilhas e grãos-de-bico).

\section{Resultados e Discussão}

\subsection{Lentilha}

A lentilha é uma leguminosa originária no Oriente Próximo e na região mediterrânea é pertencente à Família Fabacea, se destaca por ser uma cultura de alto valor nutricional, por ser uma das primeiras leguminosas a ser domesticada. Acredita-se que disseminação da lentilha seguiu a rota das técnicas agrícolas neolíticas, indo do Crescente Fértil para a Europa Central, Ocidental e Grécia, ainda para o Delta do Nilo e Leste Indiano (Vieira, 2015). Atualmente, é cultivada principalmente no Canadá, Índia e Estados Unidos, maiores produtores mundiais (FAOSTAT, 2020).

Nos últimos anos a produção mundial de grãos de lentilha vem aumentado segundo dados (FAOSTAT, 2021), que mostra que no ano 2007 a produção era 2.836 .518 toneladas, para 6.375 .732 toneladas, em 2018. O Canadá é o maior produtor mundial, com 2.092.136 toneladas, seguido da Índia, com 1.620.000 toneladas e dos Estados Unidos da América, com 381.380 toneladas. A produtividade média desses países é de 1.395 kg.ha-1, 731 kg.ha-1 e 1.312 kg.ha-1, respectivamente (FAOSTAT, 2021).

Em relação ao Brasil no ano de 2020, teve uma produção total de grão de lentilha de aproximadamente de 58 toneladas, produção bruta de 0,31 toneladas, 6 campos inscritos é uma área plantada de 26 hectares, tendo como quantitativo de campo o estado de Goiás, Rio Grande do Sul, Distrito Federal e Paraná como mostra o Gráfico 1, (IBGE, 2021). Através desses dados nós indica que há uma demanda crescente em decorrência do aumento de consumo sementes comestíveis de plantas leguminosas e a quantidade de área plantada, colhida para haver esse aumento de quantidade de grão. 
Gráfico 1: Representa a quantidade de campo por estado no ano de 2020.

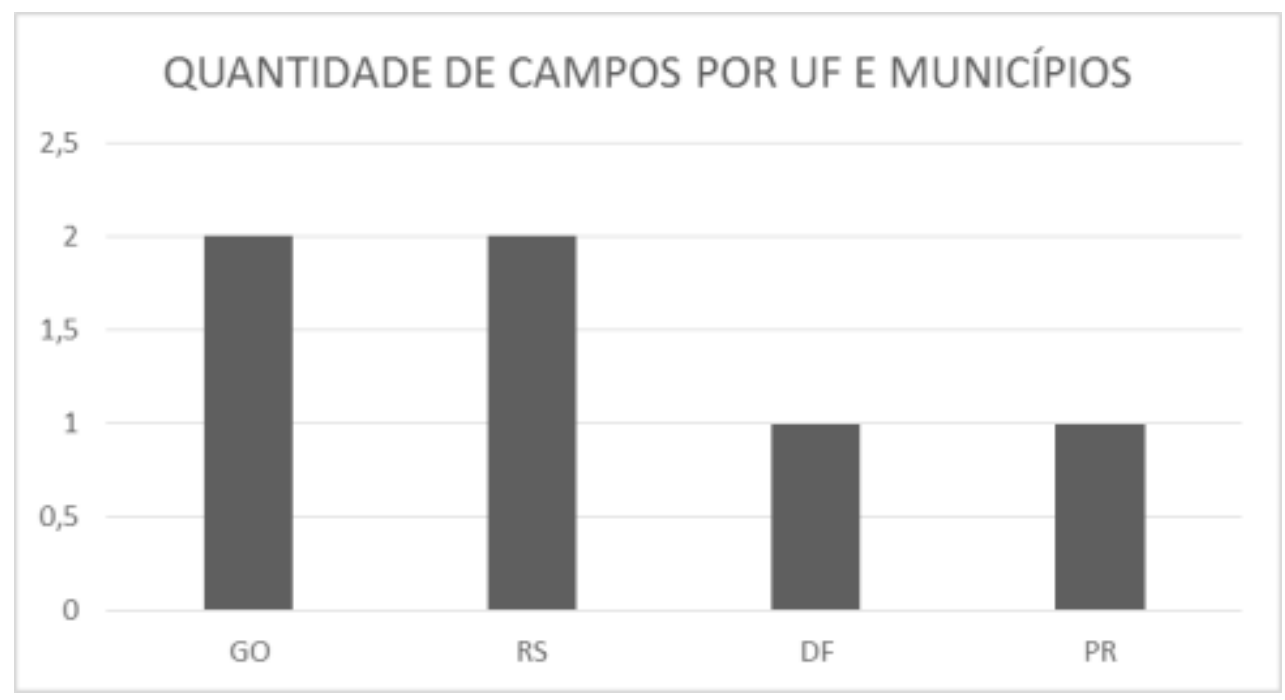

Fonte: IBGE (2021).

A perspectiva e que o mercado de lentilha no Brasil aumente o seu consumo interno e de sua produção, assim não ficamos à mercê da importação do Canadá, já que em 2018 e 2017, foram importadas 15 mil toneladas de lentilha contra 12 mil toneladas nos três anos anteriores a estes (COMEX STAT, 2021).

\subsection{Feijão}

Originaria das Américas o feijão é uma Fabaceae, que pertence ao gênero Phaseolus e possui cerca de 55 espécies, na qual as espécies mais importantes economicamente e cultivadas no Brasil é o feijão comum $(P$. vulgaris) e o feijão-fava $(P$. lunatus) (Delgado Salinas, 2000).

Evidencias botânicas e arqueológicas, bioquímica indicam que houve há 8.000 anos atrás um processo de domesticação o feijão comum silvestre para forma cultivada, esse processo se deu origem no norte do México através da América Central e da Cordilheira dos Andes ao noroeste da Argentina, por essa razão pool gênicos são reconhecidos: Mesoamericano e Andino (Bitocchi et al., 2012).

O Phaseolus Vulgares, mais conhecido como feijão comum possui uma ampla gama de produção, heterogenitissidade e desempenho agronômico, pensando nisso e a partir de informações moleculares, morfológicas e adaptativas, classificou o feijão em raças conforme o centro de domesticação, são elas: Mesoamericana (conjuntos gênicos de 1 a 4), Durango (5), 4 Jalisco (6); Nova Granada (7 a 9), Chile (10) e Peru (11 e 12). Essa classificação é muito útil para orientar os cruzamentos entre diferentes cultivares (Santos e Gavilares, 2006).

Ao contrário Phaseolus Iunatus, é conhecido como feijão- fava ele é originário especificamente da Guatemala e possui três direção de dispersão, forma, tamanho das sementes sendo: "Batata" (rota Caribenha), "Sieva" (rota Hopi) e "Lima Grande" (rota Inca). O tipo "Batata" apresenta sementes globosas e pequenas (peso de 100 sementes entre 35 e 50 g). O tipo “Sieva" inclui sementes de tamanho mediano (peso de 100 sementes de 50 a 70 g) e planas. O grupo "Lima Grande' tem grandes sementes planas (peso de 100 sementes variando de 70 a 110 g) (Castineiras et al., 1991).

Segundo a (FAO 2020), feijão comum como o feijão fava são cultivares que estão distribuídas em todos os continentes do mundo, sendo o feijão comum o mais importante socioeconomicamente e apresenta as seguintes características a planta: herbácea de raízes fibrosas, caule com mais de $1 \mathrm{~m}$ de altura, estriados e densos. Hábito de crescimento determinado ou indeterminado. Folhas com estípulas, triangulares a lanceoladas. Inflorescência de 3 a $10 \mathrm{~cm}$ de comprimento em 
pseudorracimos axilares. Cálice campanulado e dentado; corola pentâmera com a quilha enrolada em duas voltas, que resulta da fusão de duas pétalas inferiores e abriga os estames e o pistilo; há duas pétalas laterais chamadas asas e uma pétala bem maior que envolve as demais, o estandarte. A corola pode ser branca, amarela, rosada a lilás. Estames diadelfos e legume de 8,5 a 11 cm, com 5-10 sementes reniformes com várias cores e germinação epígea (Beyra e Artiles, 2004; Snak et al., 2011).

Já o feijão fava se diferencia do feijão comum pelas suas brácteas e bractéolas discretas, cálice de dentes curtos e face externa do estandarte seríceo-pubescente. São ervas volúveis anuais. Caule de 1-4,5 m de altura estriado e peludo. Inflorescência de 1,5-14 cm de comprimento. Flores menores que $10 \mathrm{~mm}$ de longitude. Cálice campanulado e seríceo externamente. Corola amarela, lilás rosada, violeta ou branca; estandarte piloso externamente; asas alongadas, quilha enrolada em até 2 espirais; 8 estames. Legume glabo com 2-4 sementes reniforme (Beyra e Artiles, 2004; Snak et al., 2011).

De acordo com o Sistema de Gestão Fundiária (SIGEF, 2021) e o (IBRAFE) - Instituto Brasileiro do Feijão e Pulses, o Brasil é considerado o maior produtor e consumidor de feijão Phaseoulus do mundo, com um total de campo inscrito de 8.426, total de produção bruta de 4.579.029,90 toneladas, total de produção estimada de 4.667.940,43 toneladas, área total de 296.156,7 hectares no ano de 2020. Sendo assim considerado o "celeiro do mundo", o Brasil, com sua imensa produção de grãos e expertise para produzir feijões, tem evoluído, exportando-os para todos os continentes, e assim os pulses ganham crescente importância no agronegócio do país. Sete entre dez brasileiros consomem feijão todos os dias, fazendo dele o pratosímbolo da nossa cultura gastronômica.

Conforme (Tabelas 1 e 2), podemos perceber que no ano de 2019, a área plantada ou destinada à colheita de grão de feijão no Brasil é de 2.376.368 hectare com produção de 2.211.698 toneladas e uma área colhida de 2.211.698 hectares. As regiões maiores produtores, segundo dados do (IBGE,2021), está o estado Paraná com 481.430 hectares de área plantada ou destinada à colheita de grão de feijão , 414.670 hectares área colhida e uma produção 414.670 toneladas em segundo está o Ceará com 380.148 hectares de área plantada ou destinada à colheita de grão de feijão, 377, 145 hectares área colhida e uma produção 377.145 toneladas, já o Rio Grande do Sul está em nonagésimo lugar com uma área plantada ou destinada à colheita de grão de feijão de 62.038 hectares, 61,418 hectares área colhida e uma produção de 61,418 toneladas. 
Tabela 1: Representa área colhida (hectares) de feijão em diferentes regiões ao longo do tempo.

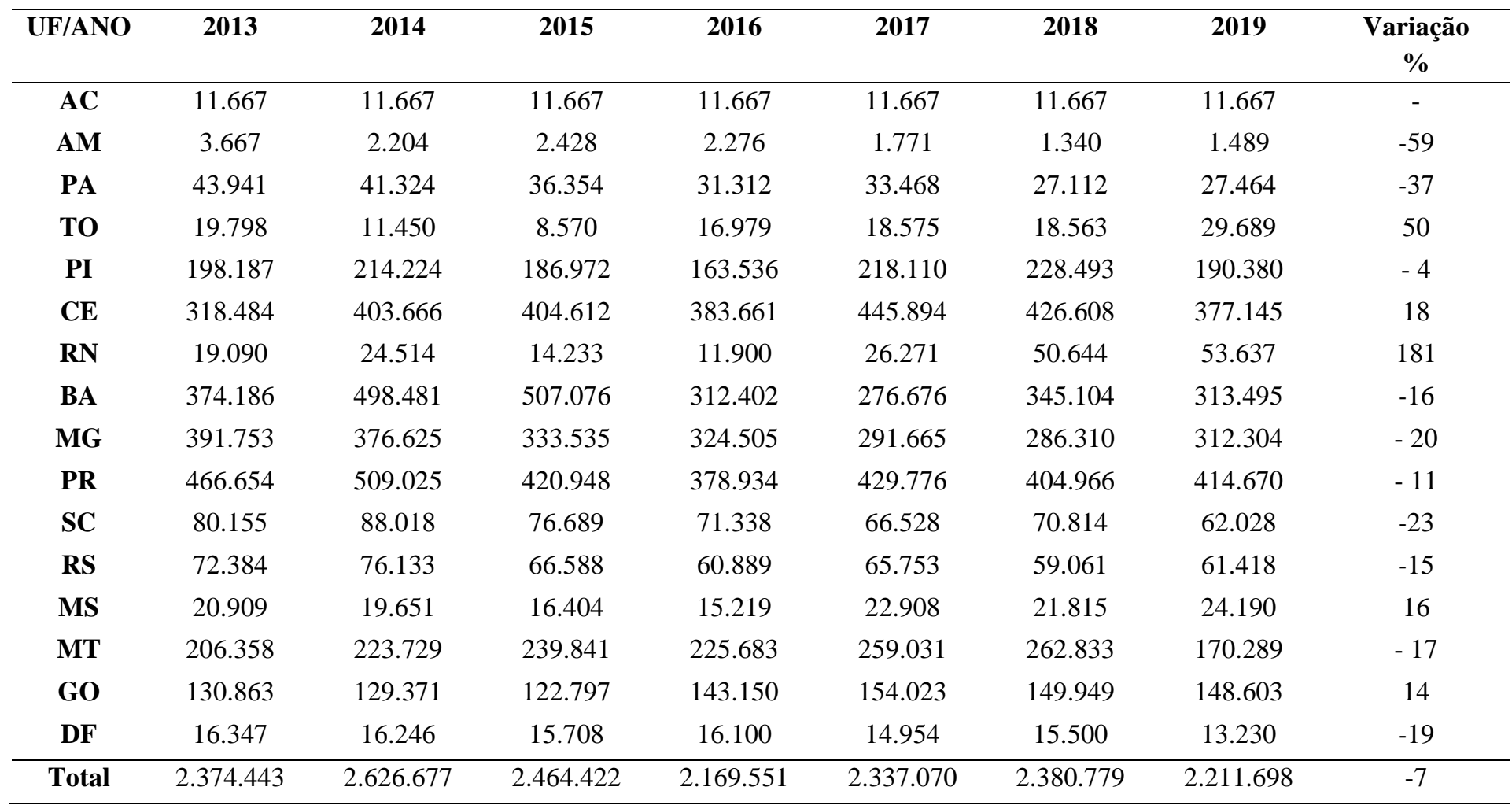


Tabela 2: Representa a quantidade produzidas (toneladas) de feijão em diferentes regiões ao longo do tempo.

\begin{tabular}{|c|c|c|c|c|c|c|c|c|}
\hline UF/ANO & 2013 & 2014 & 2015 & 2016 & 2017 & 2018 & 2019 & $\begin{array}{c}\text { Variação } \\
\%\end{array}$ \\
\hline $\mathrm{AC}$ & 11.667 & 11.667 & 11.667 & 11.667 & 11.667 & 11.667 & 11.667 & - \\
\hline $\mathbf{A M}$ & 3.667 & 2.204 & 2.428 & 2.276 & 1.771 & 1.340 & 1.489 & 59 \\
\hline PA & 43.941 & 41.324 & 36.354 & 31.312 & 33.468 & 27.112 & 27.464 & -37 \\
\hline TO & 19.798 & 11.450 & 8.570 & 16.979 & 18.575 & 18.563 & 29.689 & 50 \\
\hline PI & 198.187 & 214.224 & 186.972 & 163.536 & 218.110 & 228.493 & 190.380 & -4 \\
\hline $\mathrm{CE}$ & 318.484 & 403.666 & 404.612 & 383.661 & 445.894 & 426.608 & 377.145 & 18 \\
\hline $\mathbf{R N}$ & 19.090 & 24.514 & 14.233 & 11.900 & 26.271 & 50.644 & 53.637 & 181 \\
\hline BA & 374.186 & 498.481 & 507.076 & 312.402 & 276.676 & 345.104 & 313.495 & -16 \\
\hline MG & 391.753 & 376.625 & 333.535 & 324.505 & 291.665 & 286.310 & 312.304 & -20 \\
\hline PR & 466.654 & 509.025 & 420.948 & 378.934 & 429.776 & 404.966 & 414.670 & -11 \\
\hline SC & 80.155 & 88.018 & 76.689 & 71.338 & 66.528 & 70.814 & 62.028 & -23 \\
\hline $\mathbf{R S}$ & 72.384 & 76.133 & 66.588 & 60.889 & 65.753 & 59.061 & 61.418 & -15 \\
\hline MS & 20.909 & 19.651 & 16.404 & 15.219 & 22.908 & 21.815 & 24.190 & 16 \\
\hline MT & 206.358 & 223.729 & 239.841 & 225.683 & 259.031 & 262.833 & 170.289 & -17 \\
\hline GO & 130.863 & 129.371 & 122.797 & 143.150 & 154.023 & 149.949 & 148.603 & 14 \\
\hline DF & 16.347 & 16.246 & 15.708 & 16.100 & 14.954 & 15.500 & 13.230 & -19 \\
\hline Total & 2.374 .443 & 2.626 .677 & 2.464 .422 & 2.169 .551 & 2.337 .070 & 2.380 .779 & 2.211 .698 & -7 \\
\hline
\end{tabular}

Fonte: IBGE (2021).

De acordo com as (Tabelas 1 ou 2), sobre área colhida de grão de feijão houve uma estagnação ao longo da série histórica. Uma das inferências a partir desses resultados, é que não haverá um grande aumento na demanda de sementes de feijão, considerando esse fator. Isso não quer dizer que a produção de sementes de feijão não poderá ser aumentada. Ela pode, através de uma maior utilização de sementes certificadas.

\section{3 grão- de- bico}

O grão-de-bico (Cicer arietinum L.) é uma leguminosa que pertence à família Fabaceae, do gênero Cicer L., que originou-se no Oriente Médio, tendo chegado à Europa através das migrações e das trocas comerciais e hoje é uma cultivar de grande importância, pois tem um papel fundamental na alimentação de milhões de pessoas ao redor do mundo (WescheEbeling, 2001), pois o grão de bico é uma fonte importante de aminoácidos, minerais e proteínas utilizadas na dieta da população de baixa renda nas regiões dos trópicos semiáridos, Ásia Ocidental e Norte da África, e é particularmente importante nas dietas vegetarianas. Além disso, está cada vez mais sendo usados como um substituto da proteína animal (Icrisat, 2017).

De acordo com (Biçer, 2010), existe dois tipos distintos de grão de bico no mundo: "Kabuli” é caracterizado pela cor das sementes que são brancas ou beges com a forma da cabeça de carneiro, possuem tegumento fino e liso e as flores são brancas com ausência de pigmentação de antocianina na haste. Quando comparado com o tipo Desi, o kabuli tem níveis mais elevados de sacarose e níveis mais baixos de fibra. O tipo kabuli também é conhecido como macrosperma, e se apresenta com: 
vagens, folhas, grãos maiores, estatura mais alta e é produzido no Brasil. Já o tipo "Desi” as sementes são coloridas e protegidas por um espesso tegumento, as cores mais comuns incluem várias tonalidades e combinações de marrom, amarelo, verde e preto. As sementes são geralmente pequenas e angulares com superfície rugosa, as flores geralmente são de cor rosa e as plantas mostram diversos graus de pigmentação de antocianina nas hastes. O tipo Desi corresponde de 80-85\% da área cultivada no mundo, o seu consumo é na forma de farinhas e grãos quebrados (Gaur, 2010).

A produção do grão-de- bico vem aumentado nos últimos anos, essa expansão se deve através de desenvolvimento de novas cultivares e tecnologias, sendo que os países maiores produtores são: Índia, Paquistão, Turquia, Irã e etc. Em relação ao Brasil no ano de 2020, apresentou uma produção total estimada de 421, 28 tonelada, 11.78 toneladas de produção bruta, 235,58 hectares de área plantada de grão de bico segundo dados do (SIGEF, 2021). Conforme especialista expert no assunto a expectativa é de continuar a crescer a produção, consumo no Brasil de Cicer arietinum L.

\subsection{Ervilha}

A ervilha (Pisum sativum) é uma hortaliça pertencente à família Fabaceae, originária do Oriente Médio que ao longo dos anos sua cultura vem se difundindo pelas várias partes do mundo, através do alto valor nutritivo com amplas alternativas de uso na alimentação e pelo surgimento e novas espécies vegetais como: A ervilha-torta (Pisum sativum L. subsp. sativum var. macrocarpum Ser., ou Pisum v) e ervilha (P sativum L.) (Wutke et al., 2021).

De acordo com surgindo dessas novas espécies as ervilhas foram classificadas como: ervilhas comestíveis são comumente chamadas de ervilhas-de-jardim ou de ervilha-grão ( $P$. sativum L. sativum), que são subdivididas em lisas e rugosas e, por seu alto teor de amilose, são cultivadas apenas para a produção de amido (Schuchert, 2021). Já as ervilhas-tortas (P. sativum L. macrocarpum) possuem vagem comestível e os grãos adocicados (Stephens, 2021).

O cultivo de ervilha independente da espécie tem restrições para o seu cultivo, pois é uma hortaliça sensível a altas temperaturas principalmente as ervilhas-grão, por essa razão, são produzidas preferencialmente em regiões temperadas ou em locais de temperaturas amenas ou frias, adaptando-se às condições de outono-inverno no Centro-Sul (Filgueira, 2000).

A produção mundial de ervilhas hoje representa quase $80 \%$ da forma seca do produto, enquanto apenas $20 \%$ é comercializada como ervilha verde. No Brasil no ano de 2020, a produção de grão de ervilha- grão foi de uma área 2,45 hectares, produção estimada de 2,34 toneladas e produção bruta de 0,67 toneladas.

Conforme (Tabelas 3, 4, 5), podemos perceber que no ano de 2019, a área plantada ou destinada à colheita de grão de ervilha-grão no Brasil é de 711 hectare com produção de 2.715 toneladas e uma área colhida de 671 hectares. As regiões maiores produtores, segundo dados do (IBGE,2021), está o estado de Minas Gerais com 574 hectares de área plantada ou destinada à colheita de grão de ervilha , 574 hectares área colhida e uma produção 2.147 toneladas em segundo está o Paraná com 57 hectares de área plantada ou destinada à colheita de grão de ervilha, 57 hectares área colhida e uma produção de 190 toneladas, já o Rio Grande do Sul está em quinto lugar com uma área plantada ou destinada à colheita de grão de ervilha com 19 hectares, 19 hectares área colhida e uma produção de 36 toneladas. 
Tabela 3: Representa a área plantada ou destinada à colheita (hectares) de ervilha-grão em diferentes regiões ao longo do tempo.

\begin{tabular}{|c|c|c|c|c|c|c|c|c|}
\hline UF/ANO & 2013 & 2014 & 2015 & 2016 & 2017 & 2018 & 2019 & $\begin{array}{c}\text { Variação } \\
\%\end{array}$ \\
\hline MG & 265 & 362 & 150 & - & 542 & 560 & 574 & 54 \\
\hline SP & 10 & 239 & 11 & 13 & 10 & 30 & 21 & -27 \\
\hline PR & 66 & 18 & 56 & 58 & 54 & 62 & 57 & -59 \\
\hline RS & 918 & 1.089 & 756 & 631 & 479 & 145 & 19 & -4.813 \\
\hline DF & - & 140 & 400 & 350 & 32 & 40 & 40 & 40 \\
\hline Total & 1.259 & 1.848 & 1.373 & 1.052 & 1.117 & 837 & 711 & 534 \\
\hline
\end{tabular}

Fonte: IBGE (2021).

Tabela 4: Representa área colhida (hectares) de ervilha-grão em diferentes regiões ao longo do tempo.

\begin{tabular}{ccccccccc}
\hline UF/ANO & $\mathbf{2 0 1 3}$ & $\mathbf{2 0 1 4}$ & $\mathbf{2 0 1 5}$ & $\mathbf{2 0 1 6}$ & $\mathbf{2 0 1 7}$ & $\mathbf{2 0 1 8}$ & $\mathbf{2 0 1 9}$ & $\begin{array}{c}\text { Variação } \\
\text { \% }\end{array}$ \\
\hline MG & 265 & 362 & 150 & - & 542 & 560 & 574 & 54 \\
SP & 10 & 239 & 11 & 13 & 10 & 30 & 21 & 52 \\
PR & 66 & 18 & 56 & 58 & 54 & 62 & 57 & -16 \\
RS & 918 & 1.089 & 756 & 631 & 479 & 145 & 19 & -4.732 \\
DF & 140 & 400 & 350 & 32 & 40 & 40 & - & - \\
\hline Total & 1.399 & 2.108 & 1.323 & 734 & 1.125 & 837 & 671 & -108 \\
\hline
\end{tabular}

Fonte: IBGE (2021).

Tabela 5: Representa a quantidade produzidas (toneladas) de ervilha-grão em diferentes regiões ao longo do tempo.

\begin{tabular}{ccccccccc}
\hline UF/ANO & $\mathbf{2 0 1 3}$ & $\mathbf{2 0 1 4}$ & $\mathbf{2 0 1 5}$ & $\mathbf{2 0 1 6}$ & $\mathbf{2 0 1 7}$ & $\mathbf{2 0 1 8}$ & $\mathbf{2 0 1 9}$ & $\begin{array}{c}\text { Variação } \\
\text { \% }\end{array}$ \\
\hline MG & 710 & 1.311 & 765 & - & 2.069 & 2.014 & 2.147 & 67 \\
SP & 13 & 424 & 12 & 16 & 11 & 71 & 62 & 79 \\
PR & 166 & 73 & 156 & 182 & 160 & 198 & 190 & 13 \\
RS & 2.103 & 1.055 & 428 & 1.256 & 299 & 250 & 36 & -5.742 \\
DF & - & 829 & 1.200 & 2.165 & 224 & 280 & 280 & 100 \\
\hline Total & 2.992 & 3.692 & 2.561 & 3.619 & 2.763 & 2.813 & 2.715 & -10 \\
\hline
\end{tabular}

Fonte: IBGE (2021).

\section{Considerações Finais}

Com base nos resultados apresentados, de modo geral, a produtividade de sementes de pulses nos indica que ainda falta muitas informações, como trabalhos publicados que nos indique a quantidade de produção de sementes, desenvolvimento de tecnologias, aspectos morfológicos dentre outros, tanto do feijão como da ervilha, grão de bico, lentilha dentre outros, até mesmo de incentivos dos nossos governantes aos produtores, já que são culturas que movimenta milhões e que poderia movimentar muito mais o mercado, possibilitando a geração de mais emprego e renda aos produtores rurais. Diante desse senário apresentado é importante que futuramente se tenha mais informações e estudos como este apresentado dando mais ênfase é importância ao tema abordado. 
Research, Society and Development, v. 10, n. 12, e98101220217, 2021

(CC BY 4.0) | ISSN 2525-3409 | DOI: http://dx.doi.org/10.33448/rsd-v10i12.20217

\section{Referências}

Beyra, A., \& Artiles, G. R. (2004). Revisión taxonómica de los géneros Phaseolus y Vigna (Leguminosae-Papilionoideae) en Cuba. Anales del Jardín Botánico de Madrid. 61:135-154

Bitocchi, E., Nanni, L., Bellucci, E., Rossi, M., Giardini, A., Zeuli, P. S., Logozzo, G., Stougaard, J., Mcclean, P., Attene, G., \& Papa, R. (2012). Mesoamerican origin of the common bean (Phaseolus vulgaris L.) is revealed by sequence data. Proceedings of the National Academy of Sciences. 109: E788E796.

Biçer, B. T. \& Sakar, D. Inheritance of pod and seed traits in chickpea. Journal of Environmental Biology. Lucknow, 31(5), 667-669.

Brasil. (2021). Ministério da Agricultura, Pecuária e Abastecimento. Secretaria de Defesa Agropecuária. Regulamento da Lei nº 10.711, de 2003, aprovado

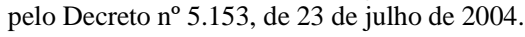

Castineiras, L., Esquivel, M., Rivero, N., \& Marino, A. (1991). Variabilidad de la semilla de Phaseolus lunatus L. en Cuba. Revista Del Jardin Botanico Nacional. 12: 109-114, 1991.

COMEX STAT. (2021). Exportação e Importação Geral. 2020. http://comexstat.mdic.gov.br/pt/geral.

Delgado, S. A. (2000). Systematics of the genus Phaseolus in Mexico and Central America. Ph.D. dissertation, University of Texas, Austin.

EMBRAPA. (2014). Cultivares da Embrapa Hortaliças (1981-2013). Embrapa Hortaliças. 182 p.

Empresa Brasileira de Pesquisa Agropecuária (EMBRAPA). (2016). Pulses - Produção, Consumo E Mercados Na Índia E Oportunidades Para O Brasil E A Embrapa. Disponível em https://www.alice.cnptia.embrapa.br/alice/bitstream/doc/1096615/1/.

Empresa Brasileira de Pesquisa Agropecuária (EMBRAPA). (2018). PULSES - Produção, Consumo, Oportunidades Para O Brasil. https://www.alice.cnptia.embrapa.br/alice/bitstream/doc/1096615/1/.

Food And Agriculture Organization Of The United Nations - FAO. Faostat database gateway. http://www.fao.org/faostat/en/\#data/QC/visualize.

FAOSTAT. (2021). Crops, produção de lentilhas no mundo. 2020. Disponível em: http://www.fao.org/faostat/en/\#data/QC/visualize.

Filgueira, F. A. R. (2000). Novo manual de olericultura: agrotecnologia moderna na produção e comercialização de hortaliças. UFV, 402p.

Gaur, P. M., Tripathi, S., Gowda, C. L. L., Ranga Rao G. V., Sharma, H. C., Pande, S., \& Sharma M. (2010). Chickpea seed production manual. Pantacheru, Andhra Pradesh, India, International Crops Research Institute for the Semi-Arid Tropics. 2010. 28 p.

IBGE. (2019). Censo Agropecuário. Tabela 1618. 2019. https://sidra.ibge.gov.br/tabela/1618\#resultado.

Santos, J. B., \& Gavillanes, M. L. (2006). Botânica. In: Vieira. C., Junior Paula, T. J., Borém, A. Feijão. (2a ed.), UFV. 41-65.

Schuchert, W. (2021). Garden Pea (Pisum sativum L.). In: University Of Hamburg. Department of Biology. Disponível em: http://www.biologie.unihamburg.de/b- online/schaugarten/pisumsativumL/Pea.html

Snak, C., Miotto, S. T. S., \& Goldenberg, R. (2011). Phaseolinae (Leguminosae, Papilionoideae, Phaseoleae) no estado do Paraná, Brasil. Rodriguésia. 62: 695-716, 2011.

Stephens, J. M. (2021) Pea, Snap - Pisum sativum L. (Macrocarpum group). In: UNIVERSITY OF FLORIDA. IFAS extension. Disponível em: http://edis.ifas.ufl.edu/MV109.

Vieira, R. F., Vieira, C., \& Andrade, G. A. (2015). Comparações agronômicas de feijões dos gêneros Vigna e Phaseolus com o feijão-comum (Phaseolus vulgaris L.). Pesquisa Agropecuária Brasileira. 27:841-850, 2015.

Wesche-Ebeling, P., Maiti, R. K., Cuevas-Hernandez \& Verde-Star, J. (2001). Food Science and Feed Quality. In: Maiti R. and Wesche-Ebeling. (Ed.). Advances in Chickpea Science. Enfield:Science Publishers, Inc., 200. 189-214.

Wutke, E. B., Ambrosano, E. D., \& Bulisani, E. A. Ervilha-de-grão. (2021). In: Instituto Agronômico. http://www.iac.sp.gov.br/Tecnologias/ ErvilhaGraos/ErvilhaGRAOS.htm. 